8

\title{
Load response of an osseointegrated implant used in the treatment of unilateral transfemoral amputation: An early implant loosening case study
}

\author{
Dale L. Robinson ${ }^{1}$, Lauren Safai ${ }^{1,2}$, Vahidreza Harandi ${ }^{1}$, Mark Graf ${ }^{4}$, Eduardo Cofré \\ Lizama $^{5}$, Peter Lee ${ }^{1}$, Mary P Galea ${ }^{5,6}$, Fary Khan ${ }^{5,6,7}$, Kwong Ming Tse ${ }^{8}$, David C. \\ Ackland $^{1}$
}
${ }^{1}$ Department of Biomedical Engineering, The University of Melbourne, Victoria, Australia; ${ }^{2}$ Department of Biomechanical Engineering, Delft University of Technology,
Delft, Netherlands; ${ }^{3}$ Department of Mechanical and Product Design Engineering, Swinburne University of Technology, Victoria, Australia; ${ }^{4}$ Department of Prosthetics and Orthotics, The Royal Melbourne Hospital, Victoria, Australia; ${ }^{5}$ Department of Medicine, The Royal Melbourne Hospital, Victoria, Australia; ${ }^{6}$ Department of Rehabilitation Medicine, The Royal Melbourne Hospital, Victoria, Australia; ${ }^{7}$ School of Public Health and Preventative Medicine, Monash University, Clayton, VIC, Australia; ${ }^{8}$ Swinburne University of Technology, Hawthorn, VIC, Australia

9
Submitted as an original article to Clinical Biomechanics Word count (Introduction through to Discussion): 3,760 
1 Keywords: lower limb amputee; osseointegration; finite element analysis; gait;

2 biomechanical model; 
2 Background: Osseointegrated implants for transfemoral amputees facilitate direct load

3 transfer between the prosthetic limb and femur; however, implant loosening is a common

4 complication, and the associated implant-bone loads remain poorly understood. This case

5 study aimed to use patient-specific computational modelling to evaluate bone-implant

6 interface loading during standing and walking in a transfemoral amputee with an

$7 \quad$ osseointegrated implant prior to prosthesis loosening and revision surgery.

8 Methods: One male transfemoral amputee with an osseointegrated implant was recruited

9 (age: 59-yrs, weight: $83 \mathrm{~kg}$ ) and computed tomography (CT) performed on the residual

10 limb approximately 3 months prior to implant failure. Gait analyses were performed, and

11 the CT images used to develop a finite element model of the patient's implant and

12 surrounding bone. Simulations of static weight bearing, and over-ground walking were

13 then performed.

14 Findings: During standing, maximum and minimum principal strains in trabecular bone

15 adjacent to the implant were $0.26 \%$ and $-0.30 \%$, respectively. Strains generated at the

16 instant of contralateral toe-off and contralateral heel strike during walking were

17 substantially higher and resulted in local trabecular bone yielding. Specifically, the

18 maximum and minimum principal strains in the thin layer of trabecular bone surrounding

19 the distal end of the implant were $1.15 \%$ and $-0.98 \%$, respectively.

20 Interpretation: Localised yielding of trabecular bone at the interface between the femur

21 and implant in transfemoral amputee osseointegrated prosthesis recipients may present a

22 risk of implant loosening due to periprosthetic bone fracture during walking. 
1 Rehabilitation exercises should aim to produce implant-bone loading that stimulates bone 2 remodelling to provide effective bone conditioning prior to ambulation. 


\section{INTRODUCTION}

Osseointegrated implants overcome a number of complications associated with

3 traditional socket-fitted prostheses for the treatment of lower limb amputation, including

4 residual limb pain and skin irritation at residual stump-socket interface, which can occur

5 in up to $62 \%$ of recipients (Gallagher Malcolm MacLachlan, Pamela, 2001; Hagberg and

6 Brånemark, 2001; Lyon et al., 2000; Mak et al., 2001). Clinical studies have shown that,

7 compared to socket-fitted prostheses, transfemoral osseointegration reduces tissue

8 damage and residual pain (M Al Muderis et al., 2016; Branemark et al., 2001; Sullivan et

9 al., 2003), while improving patient activity levels, and facilitating larger range of hip

10 joint movement (Brånemark et al., 2014; Hagberg et al., 2008, 2005). In two-year

11 follow-up studies by Brånemark et al., 2014 and Hagberg et al., 2008, implant survival

12 rates were $92 \%$ in 51 patients and $94 \%$ in 18 patients, respectively. Nebergall et al.

13 (2012) used radiostereometric analysis in 51 patients to show no significant implant

14 migration or rotation at ten-year follow-up. In contrast, a systematic review of outcomes

15 of osseointegrated prostheses for transfemoral amputation reported a maximum revision

16 rate of $67 \%$, with osseointegrated implants loosening in up to $6 \%$ of patients, and

17 periprosthetic fracture occurring in up to $9 \%$ of cases (van Eck and McGough, 2015). In a

18 study of 51 amputees with osseointegrated implants, mechanical failure of the prosthesis

19 was observed in up to $29 \%$ of cases (Brånemark et al., 2019), including damage to the

20 abutment and/or abutment screw that forms the connection between the intramedullary

21 stem and the prosthetic lower limb. Failures have also been reported to the intermedullary

22 stem, with four incidents described across 77 patients (Munjed Al Muderis et al., 2016;

23 Zimel et al., 2016). 
2 operative rehabilitation for up to six months to encourage integration of bone into the

3 implant prior to ambulation (Hagberg and Branemark, 2009). In the first phase of

4 rehabilitation, a controlled loading regime is applied to incrementally stimulate bone

5 mineralization and strength, whilst minimizing risk of implant overloading. Core and

6 limb strengthening exercises are commonly performed in conjunction with axial weight

7 bearing using a short training prosthesis, and static loads of increasing magnitude

8 gradually applied until the amputee is able to support half their bodyweight without

9 significant pain (Al Muderis et al., 2017b; Hagberg et al., 2005; Hagberg and Branemark,

10 2009). Some protocols also adopt eccentric prosthesis loading exercises to encourage

11 bone growth in directions other than axial (Hagberg and Branemark, 2009). In the second

12 phase of rehabilitation, prosthetic limbs are fitted, and parallel bars and crutches

13 employed to limit load transmission through the entire prosthesis. The patient may repeat

14 the static weight bearing tasks, and progressively introduce different phases of the gait

15 cycle until they are able to ambulate unaided (Leijendekkers et al., 2017). At present, the

16 loading patterns at the bone-implant interface during rehabilitation tasks such as static

17 weight bearing, and normal walking are poorly understood. As a consequence, over-

18 emphasis on functional rehabilitation tasks that under-load the bone in the residual limb

19 may not adequately prepare the patient for the dynamic loads during walking, and may

20 ultimately result early implant loosening or failure (Huiskes et al., 1987; Turner et al., 21 1986).

22 Finite element modeling has been used in several studies to investigate stress-

23 strain distributions and long-term remodeling of bone surrounding osseointegrated 
1 transfemoral implants (Helgason et al., 2009; Lee et al., 2008; Stenlund et al., 2017;

2 Tomaszewski et al., 2010). While these previous studies have been used to describe risk

3 of implant failure, implant loading was achieved using a resultant external force and

4 moment applied directly to the prosthesis. However, non-knee-spanning muscles

5 contribute to the linear and angular acceleration of the knee as well as knee joint-contact

6 loading via dynamic coupling (Zajac et al., 2002); replacing the forces of individual

7 muscles by an equivalent knee load may ultimately underestimate prosthesis force

8 response (Blemker et al., 2007; Herzog et al., 2003). The study by Lee et al., 2008

9 showed distinctive differences in bone-implant interface stresses between weight-bearing

10 and walking; however, the femur did not incorporate subject-specific bone geometry or

11 material properties, which would have significantly altered the magnitude and

12 distribution of the stress predictions.

13 The objective of this study was twofold. Firstly, to develop a patient-specific

14 multi-body musculoskeletal model of the residual limb of an amputee with an

15 osseointegrated prosthesis in the period before the implant loosened due to a

16 periprosthetic fracture, and secondly, to use this model to evaluate loading patterns at the

17 bone-implant interface during static weight-bearing with both a short training prosthesis

18 and the entire prosthetic limb, as well as walking with the prosthetic limb. The findings

19 of this case study will help in the development of personalised rehabilitation regimens to

20 improve bone-implant integration and minimize early implant loosening.

21

22 MATERIALS AND METHODS

23 Subject recruitment and imaging 
One male subject (age: 59 years, weight: $83 \mathrm{~kg}$, height: $1.90 \mathrm{~m}$ ) with an above-knee

2 amputation due to an automobile accident was recruited 12 months following primary

3 surgery to implant a transfemoral osseointegrated prosthesis. The implant was an

4 Osseointegrated Prosthetic Limb (OPL; Permedica s.p.a, Milan, Italy) with a cross-screw

5 design (M Al Muderis et al., 2016), connected to a Genium microprocessor controlled

6 knee (Otto Bock 3B1), a pylon with in-built torsion adaptor (Otto Bock 2R21) and

7 dynamic response foot (Otto Bock 1C60, size $28 \mathrm{~cm}$ ) (Figure 1). The subject had no

8 history of previous surgery, osteoarthritis, or pain in the residual or contralateral limb.

9 This study was approved by the University of Melbourne Human Ethics Committee and

10 written-informed consent was obtained.

11 The subject's residual limb was scanned using computed tomography (CT)

12 (Somaton Definition AS+; Siemens Healthineers, Munich, Germany) with a metal

13 artefact reduction sequence and a voxel size of $0.79 \times 0.79 \times 0.75 \mathrm{~mm}$. The three-

14 dimensional geometry of the femur and osseointegrated implant was digitally

15 reconstructed from the CT images using commercially available software (Mimics

16 version 21.0; Materialise, Leuven, Belgium). Approximately 14 months post-operatively,

17 the osseointegrated implant failed by periprosthetic fracture leading to loosening of the

18 intramedullary stem in the femoral canal, and the implant was revised to a non-cross-

19 screw design OPL. The position of the revised osseointegrated implant within the

20 intramedullary canal was similar to that of the implant used in the initial surgery, as

21 confirmed by aligning the 3D components obtained in the initial surgery with the $2 \mathrm{D}$

22 projection of the revised components from a frontal-plane x-ray (Figure 2). Since the

23 identical prosthetic limbs were used both prior to and following surgery, it is likely that 
1 the positions of the residual limb and hinge axis of the prosthetic knee remained

2 relatively unchanged.

\section{Motion capture experiments}

4 Motion analysis experiments were performed with the subject's revised

5 osseointegrated prosthesis 12 months following the revision surgery. Data collection was

6 performed with the subject standing in a relaxed pose, as well as during over-ground

7 walking at the preferred self-selected speed (Figure 3a). Three-dimensional positions of

8 retro-reflective markers placed on the subject were measured using a 9-camera motion

9 analysis system (Vicon, Oxford Metrics Ltd., UK) sampling at $120 \mathrm{~Hz}$. Ground reaction

10 force data were simultaneously acquired using three instrumented force platforms (AMTI

11 Inc., Watertown, MA) sampling at $1080 \mathrm{~Hz}$. Marker trajectories were filtered using a

12 low-pass, fourth-order Butterworth filter with a cut-off frequency of $10 \mathrm{~Hz}$, while ground

13 reaction force was filtered at $60 \mathrm{~Hz}$ using a four-order Butterworth filter.

\section{Computational modeling}

15 A rigid-body musculoskeletal model of the amputee's residual limb prior to

16 prosthesis failure was developed using a subject-specific computational modelling

17 framework (Figure 3b,c). The 12-segment, 23-degree-of-fredom rigid-body model

18 actuated by 76 Hill-type muscle-tendon units was created by scaling a generic

19 musculoskeletal model of an adult to the mass and anthropometry of the patient (Ackland

20 et al., 2012). The 3D geometry of the patient's residual femur was imported into the

21 model, and the distal femur, shank and foot segments replaced with the osseointegrated

22 implant and lower limb. The knee joint was modelled as an ideal hinge, with the external

23 torque of the microprocessor-controlled knee represented by a coordinate (reserve) 
1 actuator at the knee. Intact femoral muscles were attached to the residual femur according

2 to the centre of their tendon attachments which were located relative to bony landmarks

3 on the femur using the 3D anatomical atlas software Complete Anatomy (version 5.1.1;

4 3D4Medical, Dublin, Ireland). Surgically reconstructed muscles were re-attached to the

5 distal end of the femur using a myodesis technique and any absent or dysfunctional

6 musculature in the residual limb were removed from the model.

7 The mass and inertial properties of the residual limb segments was determined by

8 representing the associated components using geometric shapes of uniform density. The

9 residual limb above the knee was represented as the frustum of a right circular cone,

10 where the maximum and minimum circumference and height were measured with a

11 measuring tape and a uniform tissue density was assumed of $1.1 \mathrm{~g} / \mathrm{cm}^{3}$ (Smith et al.,

12 2014). The mass, centre-of-mass and mass-moment of inertia components were computed

13 for this geometry using CAD software (Solidworks, Dassault Systems, Paris, France).

14 The combined mass of the knee and pylon segments was measured using digital scales

15 and represented as a solid cylinder with dimensions equal to their maximum

16 circumference and total height, as evaluated using measuring tape. The combined knee

17 and pylon was assigned a constant density for carbon fibre material $\left(1.65 \mathrm{~g} / \mathrm{cm}^{3}\right)$, and the

18 corresponding centre of mass was set at the centre of the cylinder with the mass moment

19 of inertia calculated using standard engineering formula (Eqs 1 and 2). The foot segment

20 was modelled as a triangular prism with its height and width determined using the tape

21 measure. Assuming a uniform density of a carbon fibre material, the centre of mass and

22 mass moments of inertia were computed using the CAD software. The position of the

23 hinge axis on the prosthetic knee was determined by placing two reflective markers 
1 coincident with the rotation axis on the prosthetic limb. The correct positioning of these

2 markers on the axis was verified by examining their 3D measurements recorded by the

3 motion capture system during flexion of the prosthetic limb.

4

5

6

7

8

$$
\begin{gathered}
I_{x}=I_{y}=\frac{1}{12} m\left(3 r^{2}+h^{2}\right) \\
I_{z}=\frac{1}{2} m r^{2}
\end{gathered}
$$

where $\mathrm{I}$ is the mass moment of inertia, the subscripts $\mathrm{x}$ and $\mathrm{y}$ denote the radial directions and $\mathrm{z}$ denotes the axial direction, $\mathrm{m}$ is the mass, $\mathrm{r}$ is the radius, $\mathrm{h}$ is the cylinder height.

The musculoskeletal model was used to simulate static weight bearing conditions with a short training prosthesis as well as the prosthetic limb. Simulations of walking were also performed, specifically, four gait events during the stance phase that included ipsilateral heel strike, contralateral toe-off, contralateral heel strike and ipsilateral toe-off (Figure 4). For each simulation, inverse kinematics was applied to the motion capture data. Net internal joint moments were then calculated using inverse dynamics and decomposed into muscle forces using static optimization (Dorn et al., 2012). For static weight bearing with the short training prosthesis, $50 \%$ body-weight was applied to both the abutment of the intramedullary stem and to the foot of the intact limb.

A deformable model of the residual limb and implant was developed in a commercial finite element modelling package (Abaqus 2017; Simulia, RI, USA) (Figure 3D). The model was created and output data expressed in the femoral coordinate system, which was located at the centre of the femoral head with the y-axis pointing cranially from the prosthetic knee hinge axis centre to the femoral head centre, the $\mathrm{x}$-axis pointing anteriorly and perpendicular to the plane defined by the y-axis and the prosthetic knee 
1 hinge axis, and the $\mathrm{z}$-axis calculated as the cross-product of the $\mathrm{x}$ - and $\mathrm{y}$-axes. The three-

2 dimensional geometries of the femoral cortical bone, trabecular bone and implant were

3 meshed using tetrahedron elements using Hypermesh (version 2017.2; Altair

4 Engineering, Michigan, USA).

5 To prevent a stress concentration at the connection between the intramedullary stem

6 and cross-screw, a $0.5 \mathrm{~mm}$ fillet was added to the outer edge of the hole on the cross-

7 screw and the mesh density was increased at the interface between the components. The

8 average element size and total number of elements of each component are provided in

9 Table 1. The intramedullary stem and cross-screw were rigidly tied to one another, and

10 the thread on the screw modelled as a uniform $10 \mathrm{~mm}$ diameter cylinder. The implant and

11 bone were modelled as linear-elastic solids, with material properties for the implant set to

12 a Ti6Al4V titanium alloy (Al Muderis et al., 2017a), whilst the bone was assigned a

13 heterogeneous apparent bone mineral density $\left(\rho_{\text {app }}\right)$ with an elastic modulus derived from

14 the CT data (Table 1). The intramedullary stem and the threaded region of the cross-

15 screw were assumed to be completely osseointegrated with the surrounding bone, and

16 these surfaces were tied to prevent relative motion between respective nodes at the

17 contact interfaces. The surface of the femoral head was clamped three-dimensionally to

18 model contact against the acetabulum. This boundary condition was chosen because the

19 resultant hip joint contact force was approximately at the centre of the femoral head,

20 which ensured approximately equivalent boundary condition positions, joint forces and

21 moments with that of the musculoskeletal model. Although this clamped boundary

22 condition would have differed from joint contact in a native joint, this difference was 
1 assumed to have only a localised contribution to the femoral stress predictions in the

2 vicinity of the femoral head.

$3 \quad$ For simulations of standing (training prosthesis and entire prosthetic limb) and

4 walking, the rigid-body musculoskeletal model predictions of kinematics, inertial forces,

5 muscle forces and knee joint reaction forces were applied to the finite element model.

6 Twenty-seven muscle forces were included in the model, with each applied across several

7 nodes on the bone in the vicinity of the muscle attachment. The knee-joint reaction force

8 and moment were transmitted to the distal end of the intramedullary stem via a rigid

9 multi-point constraint (MPC). The inertial forces and moments due to linear and angular

10 femoral acceleration were applied at the distal end of the intramedullary stem. Peak von

11 Mises stresses, and maximum and minimum principal strains were calculated for the

12 implant, and femoral trabecular bone and cortical bone in four discrete femoral regions:

13 the femoral neck, intertrochanteric, subtrochanteric and diaphysis (Figure 5). A strain-

14 based failure criterion was used to identify trabecular bone yielding, whereas a stress-

15 based criterion was used to identify cortical yielding/fracture and implant yielding (Table

16 1). To verify model consistency, the hip joint reaction force calculated using the

17 musculoskeletal model was compared to the hip joint-contact force estimated using the

18 finite element model. To evaluate sensitivity of the results to changes in mesh density, the

19 entire FE model mesh density was increased to the highest amount possible

20 (approximately 3.60 million elements) and used to simulate the contralateral toe-off load

21 case (see Supplementary Material). Compared to the nominal mesh density, the stress and

22 strain predictions had an average difference less than $10 \%$ for each component, which 
1 was considered sufficient to provide reasonable comparisons between the load cases

2 considered in the current study.

\section{RESULTS}

4 The largest muscle contribution to support the residual limb during standing was

5 from adductor brevis, adductor longus, gluteus medius (anterior) and iliacus, with each

6 generating between 62.1 and $248.9 \mathrm{~N}$ (Table 2). In comparison, there were greater forces

7 generated by particular hip-spanning muscles during the stance phase of walking, with

8 peak forces greater than $500 \mathrm{~N}$ for gluteus maximus, gluteus medius, rectus femoris,

9 iliacus and psoas (Table 2). The resultant force at the abutment of the training prosthesis

10 and knee joint of the lower limb prosthesis were similar during standing (406.7 $\mathrm{N}$ and

$11375.6 \mathrm{~N}$, respectively) (Table 2), and each was less than half of the peak knee force

12 during the stance phase of walking (894.8 $\mathrm{N}$ at contralateral toe-off). While the training

13 prosthesis produced no external knee joint moment during standing, the resultant knee

14 joint moment for the lower limb prosthesis was $46.2 \%$ of the peak observed during stance

$15(41.0 \mathrm{Nm})$. The maximum linear and angular accelerations calculated for the residual

16 limb centre of mass during the stance phase of walking was $7.6 \mathrm{~m} / \mathrm{s}^{2}$ and $49.1 \mathrm{rad} / \mathrm{s}^{2}$,

17 respectively (Table 2). The hip joint contact forces predicted by the finite element model

18 were within $5 \%$ of those predicted by the rigid-body musculoskeletal model (Table 3).

19 The peak von Mises stress of the intramedullary stem when standing with the

20 training prosthesis and lower limb prosthesis occurred superiorly along the medial edge

21 of its connection with the cross-screw (132.7 MPa and 140.5 MPa, respectively) (Table

22 4) (Figure 6). In contrast, the peak stress on the intramedullary stem increased from 39.8

$23 \mathrm{MPa}$ at ipsilateral heel strike to $522.8 \mathrm{MPa}$ at contralateral toe-off, before decreasing to 
$125.6 \mathrm{MPa}$ at ipsilateral toe-off. The peak stresses at the cross-screw when standing with

2 the training or lower limb prosthesis (126.8 $\mathrm{MPa}$ and $131.0 \mathrm{MPa}$, respectively), were

3 much lower than the peak stress incurred during stance in this region (501.8 MPa at

4 contralateral toe-off).

$5 \quad$ For femoral cortical bone, the peak von Mises stress in each region of the femur

6 ranged from 6.1 $\mathrm{MPa}$ to $23.2 \mathrm{MPa}$ for the training prosthesis and $10.3 \mathrm{MPa}$ to $41.1 \mathrm{MPa}$

7 for the lower limb prosthesis during standing (Table 4). During stance, the

8 intertrochanteric region and diaphysis had a peak cortical stress at contralateral toe-off of

$998.0 \mathrm{MPa}$ and $78.4 \mathrm{MPa}$, respectively, whilst the femoral neck and subtrochanteric region

10 had a peak stress at contralateral heel-strike of $74.8 \mathrm{MPa}$ and $82.6 \mathrm{MPa}$, respectively.

11 During walking and standing, the stresses in femoral cortical bone were lower than those

12 of the yield strength of cortical bone (Table 1). The peak stresses in the cortical bone

13 occurred in the vicinity of muscle attachments on the greater and lesser trochanter and at

14 the distal end of the diaphysis, although large stresses were also apparent in the femoral

15 neck for contralateral toe-off and contralateral heel strike (Figure 7).

16 Considering all regions of the femur during standing with the training prosthesis,

17 the trabecular bone had a maximum and minimum principal strain of $0.25 \%$ and $-0.20 \%$,

18 respectively (Table 4). These strains were slightly greater for the load case with the lower

19 limb prosthesis $(0.54 \%$ and $-0.38 \%$, respectively). During walking, a maximum principal

20 strain of $1.15 \%$ was observed in the diaphysis at contralateral heel-strike, while a

21 minimum principal strain of $-0.80 \%$ occurred in the diaphysis at contralateral toe-off.

22 Strains at or slightly below these maxima were observed in the thin layer of trabecular

23 bone that was present at the interface the implant (Table 4), specifically at the most distal 
1 region of the femur (Figure 8). The peak strains during standing did not result in

2 trabecular bone damage, whereas there were localised regions of bone yielding observed

3 during the stance phase of walking (Table 1) (Figure 8).

\section{DISCUSSION}

5 The objective of this case study was to employ patient-specific multi-body

6 musculoskeletal modelling to evaluate the load response of an osseointegrated

7 transfemoral implant prior to its failure due to loosening. This was achieved by

8 quantifying forces, stresses and strains generated during static weight bearing with a

9 training prosthesis and full lower limb prosthesis, as well as during over-ground walking

10 with the lower limb prosthesis. While post-operative static-weight bearing tasks are

11 performed to condition femoral bone prior to ambulation, there is paucity of quantitative

12 data describing resultant loads at the implant-bone interface in osseointegrated

13 transfemoral prostheses. In the present study, the predicted loads during walking may

14 have contributed to failure of the implant-bone fixation after surgery. The findings

15 emphasise the importance of correct prosthesis selection and intraoperative placement, as

16 well as rigorous post-operative rehabilitation prior to ambulation.

17 The osseointegrated implant experienced the largest stresses at the boundary

18 between the intermedullary stem and screw, and the abutment (Figure 6). This finding

19 may be due to the presence of a prominent bending moment, since the length of the stem

20 and diaphysis provide a considerable moment arm of the distally-located forces at knee

21 joint force. Although the stresses at these locations were below the yielding threshold, it

22 is nonetheless suggested that future osseointegrated implant designs mitigate these

23 dynamic bending-generated loads, for example, using alternative implant geometry such 
1 as support ribs or radiused edges, or by using less-stiff biomaterials such as 3D printed

2 lattice structures (Chen et al., 2016). Although the locations of the observed peak stresses

3 in the cortical bone tended to occur at the muscle attachments (Figure 7), this result was

4 likely due to the small attachment areas assumed in the finite element model (Polgar et

5 al., 2003). The small attachment regions were applied to achieve the same moment arms

6 of the muscles in the musculoskeletal model which act as point loads. Despite this result,

7 the relatively large stresses observed in the femoral neck during contralateral toe-off and

8 contralateral heel-strike are consistent with studies examining peak stresses in the

9 proximal femur during stance (Martelli et al., 2014; Van Rietbergen et al., 2003).

10 No previous studies have described failures related to the cross-screw, which was

11 the location of the greatest implant stresses in the current study. However, this design is

12 only available in the OPL implant system and is applied to short femurs less than $16 \mathrm{~cm}$

13 in length (Al Muderis et al., 2018), and thus a limited number of individuals have

14 received this implant which inherently restricts the number of patients that would

15 experience potential implant failure. Further, mechanical failures of implanted

16 osseointegrated components without a cross-screw are relatively rare, with only four

17 cases on intramedullary stem failure reported across 77 patients in two studies (M Al

18 Muderis et al., 2016; Zimel et al., 2016). These studies either did not specify the implant

19 failure location or used a considerably different implant design, which prevents a direct

20 comparison to the peak implant stress locations in the current study. Mechanical failure

21 has been reported in the OPRA implant system at the abutment and/or abutment screw

22 that connects to the intramedullary stem and extends out from the bone and skin

23 (Brånemark et al., 2019). Indeed, the peak stress in the intermedullary stem was observed 
1 in a similar distal location, external to the bone (163.8 MPa at contralateral toe-off; Table

2 4), which is in close agreement with the stress distributions predicted in the current study.

3 During the single-support phase of stance, the maximum and minimum principal

4 strains for the trabecular bone were sufficient to induce yielding in the femoral neck,

5 intertrochanteric and diaphysis regions (Table 4). In most cases, these were localized to

6 small regions at the interface between the bone and the implant, especially for trabecular

7 bone that appeared to have formed at the distal end of the diaphysis (Figure 8). Localised

8 yielding or microdamage may initiate bone remodeling that potentially strengthens the

9 bone in the vicinity of the implant (Burr et al., 1997; Leucht et al., 2007; Nagaraja et al.,

10 2005). Conversely, excessive yielding may present a risk of periprosthetic bone fracture,

11 or implant migration that may lead to aseptic loosening (Taylor and Prendergast, 2015).

12 The predicted bone yielding sites at the proximal and distal regions of the femur compare

13 well with reported fracture locations associated with osseointegrated implantation where

14 femoral fractures occurred proximal from the implant (Al Muderis et al., 2018; Munjed

15 Al Muderis et al., 2016; Juhnke et al., 2015), or periprosthetic fractures occurred in the

16 proximal or distal region of bone surrounding the implant (McGough et al., 2017; Tyler

17 et al., 2009; Zimel et al., 2016). It is not possible to compare the yielding sites with cases

18 of aseptic loosening, as the initial site of implant loosening has not been reported and

19 cannot easily be determined retrospectively. A comparison between the predicted

20 yielding sites and implant loosening would be well suited to mechanical testing on

21 cadaveric specimens using dynamic imaging techniques such as dual plane fluoroscopy

22 (Tsai et al., 2013), and is recommended in future work. 
In the present study it was observed that femoral stresses and strains for each of

2 the static weight bearing conditions were much lower than those during walking (Figure

3 8) and were below the thresholds necessary to induce trabecular or cortical bone yielding.

4 Therefore, the standing-based rehabilitation task investigated may be considered

5 inadequate to stimulate bone remodelling to sufficiently condition bone prior to walking.

6 Pre-rehabilitation strategies ought to be developed to gradually introduce bone strains

7 closer to those during walking to promote more extensive bone remodelling, for example

8 sit-to-stand, step-up or squat tasks (Martelli et al., 2014).

9 The results presented in this study are in reasonable agreement with previous

10 finite element analyses of transfemoral osseointegranted implants. The peak stress

11 observed at the distal end of the intermedullary stem at contralateral toe-off (161.7 MPa;

12 Figure 5), was in reasonable agreement with the reported a peak stress of a transfemoral

13 osseointegrated implant of $137 \mathrm{MPa}$ at its distal end during midstance (Xu et al., 2006).

14 Another finite element modeling study of an osseointegrated implant found that the peak

15 von Mises stress of bone surrounding the implant was $8.5 \mathrm{MPa}$, occurring at late stance

16 (Lee et al., 2008), which is similar to the peak stress observed for this region in the

17 current study of 10.6 MPa at contralateral heel strike. Finally, a previous modelling study

18 predicted a peak von Mises equivalent strain in the diaphysis of an osseointegrated

19 implant of $0.18 \%$ ( $\mathrm{Xu}$ et al., 2016). This was of a similar magnitude to our peak strains

20 predicted in the diaphysis for the training prosthesis (maximum, minimum principal

21 strain: $0.25 \%,-0.14 \%$ ) and full lower limb prosthesis during standing (maximum,

22 minimum principal strain: $0.28 \%,-0.20 \%$ ). While the peak strains predicted in the current

23 study for stance were much greater, this may be due to the large bending moment 
1 generated by the microprocessor-controlled knee (approximately $40 \mathrm{Nm}$ at contralateral

2 toe-off), which was not modeled in the study of Xu et al. (2016).

3 There are limitations of this study that ought to be considered. First, it is unclear

4 whether the regions of low bone density at the bone-implant interface represented the true

5 bone properties or were the consequence of CT artifacts from the metallic implant such as

6 beam hardening, photon starvation or scatter (Pessis et al., 2013). However, a metal

7 artefact reduction algorithm was used to minimise this undesirable effect, though artefact

8 may still affect the CT measurements of bone density close to the implant (Koff et al.,

9 2017; Wellenberg et al., 2018). Second, the tied contact between the implant and bone

10 simulated the case of complete osseointegration of the implant and did not consider the

11 possibility of micro-motion at the bone-implant interface. Third, the thread on the implant

12 was not modeled to avoid stress discontinuities, which may have affected the stress

13 distribution in the vicinity of the bone-implant interface. Finally, due to radiation dosage,

14 a CT scan was not performed following the implant revision surgery; however, the

15 revised implant position was assessed using a frontal-plane x-ray. Comparing the 3D

16 alignment of the initial implant with the $2 \mathrm{D}$ projection of the revised implant indicated

17 that the alignment was similar (Figure 2), suggesting the revised implant was press-fit

18 into the intramedullary canal and that its position was not substantially altered in the

19 revision surgery.

20 The present study investigated loading on a transfemoral osseointegrated

21 prosthesis that, after 14 months post-operatively, failed by early loosening and was

22 subsequently revised. By using multi-body musculoskeletal modelling, it was shown that

23 strains at the prosthesis-bone interface during standing were substantially lower than 
1 those generated during walking. Localised regions of yielding of trabecular bone in the

2 vicinity of the distal femur were observed during walking, which may ultimately present

3 risk of periprosthetic fracture or implant migration, particularly in cases of insufficient

4 osseointegration and over-emphasis on static weight bearing prior to ambulation.

5 Personalised rehabilitation protocols that target unassisted ambulation ought to involve

6 dynamic tasks that transition the osseointegrated limb between low intensity static

7 weight-bearing and those associated with walking.

8 


\section{REFERENCES}

Ackland, D.C., Lin, Y.-C., Pandy, M.G., 2012. Sensitivity of model predictions of muscle function to changes in moment arms and muscle-tendon properties: a Monte-Carlo analysis. J. Biomech. 45, 1463-1471.

Al Muderis, M., Khemka, A., Lord, S.J., Van De Meent, H., Frolke, J.P.M., 2016. Safety of osseointegrated implants for transfemoral amputees: A two-center prospective cohort study. J. Bone Jt. Surg. - Am. Vol. 98, 900-909. https://doi.org/10.2106/JBJS.15.00808

Al Muderis, M., Lu, W., Glatt, V., Tetsworth, K., 2018. Two-Stage Osseointegrated Reconstruction of Post-traumatic Unilateral Transfemoral Amputees. Mil. Med. 183, 496-502. https://doi.org/10.1093/milmed/usx185

Al Muderis, M., Lu, W., Li, J.J., 2017a. Osseointegrated Prosthetic Limb for the treatment of lower limb amputationsDas Osseointegrated Prosthetic Limb zur Behandlung von Amputationen der unteren Extremitäten. Unfallchirurg 120, 306311. https://doi.org/10.1007/s00113-016-0296-8

Al Muderis, M., Lu, W., Tetsworth, K., Bosley, B., Li, J.J., 2017b. Single-stage osseointegrated reconstruction and rehabilitation of lower limb amputees: the Osseointegration Group of Australia Accelerated Protocol-2 (OGAAP-2) for a prospective cohort study. BMJ Open 7, e013508.

Al Muderis, M., Tetsworth, K., Khemka, A., Wilmot, S., Bosley, B., Lord, S.J., Glatt, V., 2016. The Osseointegration Group of Australia Accelerated Protocol (OGAAP-1) for two-stage osseointegrated reconstruction of amputated limbs. Bone Joint J. 98, 
2 Blemker, S.S., Asakawa, D.S., Gold, G.E., Delp, S.L., 2007. Image-based

952-960. musculoskeletal modeling: applications, advances, and future opportunities. J. Magn. Reson. Imaging An Off. J. Int. Soc. Magn. Reson. Med. 25, 441-451.

Brånemark, R., Berlin, Ö., Hagberg, K., Bergh, P., Gunterberg, B., Rydevik, B., 2014. A novel osseointegrated percutaneous prosthetic system for the treatment of patients with transfemoral amputation: A prospective study of 51 patients. Bone Joint J. 96, $106-113$.

Branemark, R., Branemark, P.I., Rydevik, B., Myers, R.R., 2001. Osseointegration in skeletal reconstruction and rehabilitation: a review. J. Rehabil. Res. Dev. 38, 175182.

Brånemark, R.P., Hagberg, K., Kulbacka-Ortiz, K., Berlin, Ö., Rydevik, B., 2019. Osseointegrated Percutaneous Prosthetic System for the Treatment of Patients With Transfemoral Amputation: A Prospective Five-year Follow-up of Patient-reported Outcomes and Complications. J. Am. Acad. Orthop. Surg. 27, e743-e751. https://doi.org/10.5435/JAAOS-D-17-00621

Burr, D.B., Forwood, M.R., Fyhrie, D.P., Martin, R.B., Schaffler, M.B., Turner, C.H., 1997. Bone microdamage and skeletal fragility in osteoporotic and stress fractures. J. Bone Miner. Res. 12, 6-15.

Carter, D.R., Caler, W.E., Spengler, D.M., Frankel, V.H., 1981. Fatigue behavior of adult cortical bone: the influence of mean strain and strain range. Acta Orthop. Scand. 52, 
2 Chen, W.M., Xie, Y.M., Imbalzano, G., Shen, J., Xu, S., Lee, S.J., Lee, P.V.S., 2016.

3 Lattice Ti structures with low rigidity but compatible mechanical strength: Design of

$4 \quad$ implant materials for trabecular bone. Int. J. Precis. Eng. Manuf. 17, 793-799.

$5 \quad$ https://doi.org/10.1007/s12541-016-0097-6

6 Dorn, T.W., Lin, Y.-C., Pandy, M.G., 2012. Estimates of muscle function in human gait

7 depend on how foot-ground contact is modelled. Comput. Methods Biomech.

$8 \quad$ Biomed. Engin. 15, 657-668.

9 Gallagher Malcolm MacLachlan, Pamela, D.A., 2001. Phantom limb pain and residual 10 limb pain following lower limb amputation: a descriptive analysis. Disabil. Rehabil. $11 \quad 23,522-530$.

12 Hagberg, K., Branemark, R., 2009. One hundred patients treated with osseointegrated 13 transfemoral amputation prostheses--rehabilitation perspective. J. Rehabil. Res. Dev. $14 \quad 46,331-345$.

15 Hagberg, K., Brånemark, R., 2001. Consequences of non-vascular trans-femoral 16 amputation: A survey of quality of life, prosthetic use and problems. Prosthet. 17 Orthot. Int. 25, 186-194.

18 Hagberg, K., Brånemark, R., Gunterberg, B., Rydevik, B., 2008. Osseointegrated trans-

19 femoral amputation prostheses: prospective results of general and condition-specific 20 quality of life in 18 patients at 2-year follow-up. Prosthet. Orthot. Int. 32, $29-41$.

21 Hagberg, K., Häggström, E., Uden, M., Brånemark, R., 2005. Socket versus bone- 
anchored trans-femoral prostheses: hip range of motion and sitting comfort. Prosthet. Orthot. Int. 29, 153-163.

Helgason, B., Pálsson, H., Rúnarsson, T.P., Frossard, L., Viceconti, M., 2009. Risk of failure during gait for direct skeletal attachment of a femoral prosthesis: a finite element study. Med. Eng. Phys. 31, 595-600.

Herzog, W., Clark, A., Wu, J., 2003. Resultant and local loading in models of joint disease. Arthritis Care Res. Off. J. Am. Coll. Rheumatol. 49, 239-247.

Huiskes, R., Weinans, H., Grootenboer, H.J., Dalstra, M., Fudala, B., Slooff, T.J., 1987. Adaptive bone-remodeling theory applied to prosthetic-design analysis. J. Biomech. $20,1135-1150$.

Juhnke, D., Beck, J.P., Jeyapalina, S., Aschoff, H.H., 2015. of Artificial Limb Attachment System. J. Rehabil. Res. Dev. 52, 407-420.

Koff, M.F., Burge, A.J., Koch, K.M., Potter, H.G., 2017. Imaging near orthopedic hardware. J. Magn. Reson. Imaging 46, 24-39. https://doi.org/10.1002/jmri.25577

Lee, W.C.C., Doocey, J.M., Brånemark, R., Adam, C.J., Evans, J.H., Pearcy, M.J., Frossard, L.A., 2008. FE stress analysis of the interface between the bone and an osseointegrated implant for amputees-implications to refine the rehabilitation program. Clin. Biomech. 23, 1243-1250.

Leijendekkers, R.A., van Hinte, G., Nijhuis-van der Sanden, M.W., Staal, J.B., 2017. Gait rehabilitation for a patient with an osseointegrated prosthesis following transfemoral amputation. Physiother. Theory Pract. 33, 147-161. 
2 Leucht, P., Kim, J.-B., Wazen, R., Currey, J.A., Nanci, A., Brunski, J.B., Helms, J.A., 3 2007. Effect of mechanical stimuli on skeletal regeneration around implants. Bone $4 \quad 40,919-930$.

5 Lyon, C.C., Kulkarni, J., Zimersonc, E., Van Ross, E., Beck, M.H., 2000. Skin disorders 6 in amputees. J. Am. Acad. Dermatol. 42, 501-507.

7 Mak, A.F.T., Zhang, M., Boone, D.A., 2001. State-of-the-art research in lower-limb 8 prosthetic biomechanics-socket interface: a review. J. Rehabil. Res. Dev. 38, 1619174.

10 Martelli, S., Kersh, M.E., Schache, A.G., Pandy, M.G., 2014. Strain energy in the 11 femoral neck during exercise. J. Biomech. 47, 1784-1791.

12 https://doi.org/10.1016/j.jbiomech.2014.03.036

13 McGough, R.L., Goodman, M.A., Randall, R.L., Forsberg, J.A., Potter, B.K., Lindsey, 14 B., 2017. The Compress ${ }^{\circledR}$ transcutaneous implant for rehabilitation following limb 15 amputation. Unfallchirurg 120, 300-305. https://doi.org/10.1007/s00113-017-0339169

17 Morgan, E.F., Bayraktar, H.H., Keaveny, T.M., 2003. Trabecular bone modulus-density 18 relationships depend on anatomic site. J. Biomech. 36, 897-904.

19 https://doi.org/10.1016/S0021-9290(03)00071-X

20 Morgan, E.F., Keaveny, T.M., 2001. Dependence of yield strain of human trabecular 21 bone on anatomic site. J. Biomech. 34, 569-577. https://doi.org/10.1016/S0021- 
2 Nagaraja, S., Couse, T.L., Guldberg, R.E., 2005. Trabecular bone microdamage and

3 microstructural stresses under uniaxial compression. J. Biomech. 38, 707-716.

$4 \quad$ https://doi.org/10.1016/j.jbiomech.2004.05.013

5 Oldani, C., Dominguez, A., 2012. Titanium as a Biomaterial for Implants, in: Recent

6 Advances in Arthroplasty. InTechOpen.

7 Pessis, E., Campagna, R., Sverzut, J.-M., Bach, F., Rodallec, M., Guerini, H., Feydy, A.,

8 Drapé, J.-L., 2013. Virtual monochromatic spectral imaging with fast kilovoltage

9 switching: reduction of metal artifacts at CT. Radiographics 33, 573-583.

10 Polgar, K., Gill, H.S., Viceconti, M., Murray, D.W., O’connor, J.J., 2003. Strain

11 distribution within the human femur due to physiological and simplified loading:

12 finite element analysis using the muscle standardized femur model. Proc. Inst.

13 Mech. Eng. Part H J. Eng. Med. 217, 173-189.

14 Smith, J.D., Ferris, A.E., Heise, G.D., Hinrichs, R.N., Martin, P.E., 2014. Oscillation and

15 Reaction Board Techniques for Estimating Inertial Properties of a Below-knee

16 Prosthesis 1-15. https://doi.org/10.3791/50977

17 Stenlund, P., Trobos, M., Lausmaa, J., Brånemark, R., Thomsen, P., Palmquist, A., 2017.

18 Effect of load on the bone around bone-anchored amputation prostheses. J. Orthop.

$19 \quad$ Res. 35, 1113-1122.

20 Sullivan, J., Uden, M., Robinson, K.P., Sooriakumaran, S., 2003. Rehabilitation of the

21 trans-femoral amputee with an osseointegrated prosthesis: The United Kingdom 
experience. Prosthet. Orthot. Int. 27, 114-120.

2 Taylor, M., Prendergast, P.J., 2015. Four decades of finite element analysis of

3 orthopaedic devices: Where are we now and what are the opportunities? J.

$4 \quad$ Biomech. 1-12. https://doi.org/10.1016/j.jbiomech.2014.12.019

5 Tomaszewski, P.K., Verdonschot, N., Bulstra, S.K., Verkerke, G.J., 2010. A comparative

6 finite-element analysis of bone failure and load transfer of osseointegrated

7 prostheses fixations. Ann. Biomed. Eng. 38, 2418-2427.

8 Tsai, T.-Y., Li, J.-S., Wang, S., Lin, H., Malchau, H., Li, G., Rubash, H., Kwon, Y.-M.,

9 2013. A novel dual fluoroscopic imaging method for determination of THA

10 kinematics: in-vitro and in-vivo study. J. Biomech. 46, 1300-1304.

11 Turner, T.M., Sumner, D.R., Urban, R.M., Rivero, D.P., Galante, J.O., 1986. A

12 comparative study of porous coatings in a weight-bearing total hip-arthroplasty

13 model. J. Bone Joint Surg. Am. 68, 1396-1409.

14 Tyler, W.K., Healey, J.H., Morris, C.D., Boland, P.J., O’Donnell, R.J., 2009. Compress

15 ® periprosthetic fractures: Interface stability and ease of revision. Clin. Orthop.

16 Relat. Res. 467, 2800-2806. https://doi.org/10.1007/s11999-009-0946-z

17 van Eck, C.F., McGough, R.L., 2015. Clinical outcome of osseointegrated prostheses for

18 lower extremity amputations: a systematic review of the literature. Curr. Orthop.

19 Pract. 26, 349-357.

20 Van Rietbergen, B., Huiskes, R., Eckstein, F., Rüegsegger, P., 2003. Trabecular bone

21 tissue strains in the healthy and osteoporotic human femur. J. Bone Miner. Res. 18, 

$1781-1788$.

2 Wellenberg, R.H.H., Hakvoort, E.T., Slump, C.H., Boomsma, M.F., Maas, M.,

3 Streekstra, G.J., 2018. Metal artifact reduction techniques in musculoskeletal CT-

$4 \quad$ imaging. Eur. J. Radiol.

5 Xu, D.H., Crocombe, A.D., Xu, W., 2016. Numerical evaluation of bone remodelling

6 associated with trans-femoral osseointegration implant-A 68 month follow-up

7 study. J. Biomech. 49, 488-492.

$8 \mathrm{Xu}, \mathrm{W} ., \mathrm{Xu}, \mathrm{D} . \mathrm{H}$. , Crocombe, A.D., 2006. Three-dimensional finite element stress and 9 strain analysis of a transfemoral osseointegration implant. Proc. Inst. Mech. Eng.

10 Part H J. Eng. Med. 220, 661-670.

11 Zajac, F.E., Neptune, R.R., Kautz, S.A., 2002. Biomechanics and muscle coordination of 12 human walking: Part I: Introduction to concepts, power transfer, dynamics and 13 simulations. Gait Posture 16, 215-232.

14 Zimel, M.N., Farfalli, G.L., Zindman, A.M., Riedel, E.R., Morris, C.D., Boland, P.J., 15 Healey, J.H., 2016. Revision Distal Femoral Arthroplasty With the Compress ® 16 Prosthesis Has a Low Rate of Mechanical Failure at 10 Years. Clin. Orthop. Relat. 17 Res. 474, 528-536. https://doi.org/10.1007/s11999-015-4552-y 


\section{TABLES}

Table 1: Material properties, average element size and number of elements used in the finite element model of the transfemoral amputee's residual limb, including osseointegrated prosthesis and femoral cortical and trabecular bone.

\begin{tabular}{|c|c|c|c|c|c|c|c|c|}
\hline Component & Material & $\begin{array}{l}\text { Density } \\
\left(\mathrm{g} / \mathrm{cm}^{3}\right)\end{array}$ & $\begin{array}{l}\text { Elastic } \\
\text { modulus } \\
(\mathrm{GPa})\end{array}$ & $\begin{array}{l}\text { Poisson's } \\
\text { ratio }\end{array}$ & Yield limit & $\begin{array}{l}\text { Ultimate } \\
\text { strength }\end{array}$ & $\begin{array}{c}\text { Average } \\
\text { element size } \\
(\mathrm{mm})\end{array}$ & $\begin{array}{c}\text { Number of } \\
\text { finite } \\
\text { elements }\end{array}$ \\
\hline $\begin{array}{l}\text { Intramedullary } \\
\text { stem }\end{array}$ & Ti6Al4V & 4.4 & 115 & 0.33 & $\sigma=795 \mathrm{MPa}$ & $\sigma=860 \mathrm{MPa}$ & 0.37 & 715,217 \\
\hline Cross-screw & Ti6Al4V & 4.4 & 115 & 0.33 & $\sigma=795 \mathrm{MPa}$ & $\sigma=860 \mathrm{MPa}$ & 0.23 & 544,653 \\
\hline \multirow{3}{*}{ Femur } & \multirow[t]{2}{*}{ Trabecular bone ${ }^{b}$} & \multirow[t]{2}{*}{$0.0-1.0^{b}$} & \multirow[t]{2}{*}{$0.5-5.7^{c}$} & \multirow[t]{2}{*}{0.3} & $\varepsilon_{\mathrm{Y}, \mathrm{comp}}=0.70 \%$ & N/A & 0.85 & 587,105 \\
\hline & & & & & $\varepsilon_{\mathrm{Y}, \text { tens }}=0.61 \%$ & N/A & \multirow[b]{2}{*}{0.84} & \multirow[b]{2}{*}{119,910} \\
\hline & Cortical bone ${ }^{b}$ & $1.0-2.0^{\mathrm{b}}$ & $5.7-19.7^{\mathrm{c}}$ & 0.3 & $\sigma=121.0 \mathrm{MPa}$ & $\begin{array}{c}\sigma=140.0 \\
\mathrm{MPa}\end{array}$ & & \\
\hline
\end{tabular}

\footnotetext{
a Ti6Al4V properties from (Oldani and Dominguez, 2012)

${ }^{\mathrm{b}}$ Bone densities corresponds to apparent bone mineral density ( $\rho_{\mathrm{app}}$ ) scaled linearly from CT grayscale values to the normal range of femur (Morgan et al., 2003). The threshold for $\rho_{\text {app }}$ between trabecular and cortical bone was set as $1.0 \mathrm{~g} / \mathrm{cm}^{3}$. Elastic modulus was calculated from apparent bone mineral density using $E=6850 \rho_{\text {app }}{ }^{1.49}$ (Morgan et al., 2003). The yield strains for trabecular and bone were previously published (Morgan and Keaveny, 2001), as were the yield and ultimate stress for cortical bone (Carter et al., 1981).
} 
Table 2: Magnitudes of the muscle forces $(\mathrm{N})$ calculated using the patient-specific musculoskeletal model and used in the finite element model simulations of over-ground walking and a static standing posture.

\begin{tabular}{|c|c|c|c|c|c|c|c|}
\hline \multirow[b]{2}{*}{ Component } & \multirow[b]{2}{*}{ Quantity } & \multicolumn{6}{|c|}{ Gait event } \\
\hline & & $\begin{array}{c}\text { Standing: } \\
\text { Training } \\
\text { prosthesis }\end{array}$ & $\begin{array}{l}\text { Standing: } \\
\text { Full lower } \\
\text { limb } \\
\text { prosthesis }\end{array}$ & $\begin{array}{l}\text { Ipsilateral heel } \\
\text { strike }\end{array}$ & $\begin{array}{c}\text { Contralateral } \\
\text { toe-off }\end{array}$ & $\begin{array}{c}\text { Contralateral } \\
\text { heel strike }\end{array}$ & $\begin{array}{l}\text { Ipsilateral } \\
\text { toe-off }\end{array}$ \\
\hline Adductor Brevis & \multirow{20}{*}{$\begin{array}{l}\text { Resultant force } \\
\text { (N) }\end{array}$} & 70.5 & 102.5 & 0.0 & 0.0 & 0.0 & 24.6 \\
\hline Adductor Longus & & 167.7 & 248.9 & 0.0 & 0.0 & 0.0 & 16.9 \\
\hline Adductor Magnus (Superior) & & 26.9 & 39.3 & 0.0 & 0.0 & 0.0 & 21.6 \\
\hline Adductor Magnus (Medial) & & 9.1 & 12.4 & 0.0 & 0.0 & 0.0 & 10.4 \\
\hline Adductor Magnus (Inferior) & & 37.7 & 48.2 & 0.0 & 0.2 & 0.0 & 33.7 \\
\hline Biceps Femoris Long Head & & 0.0 & 0.0 & 16.9 & 189.2 & 0.0 & 39.9 \\
\hline Gemellus & & 0.0 & 0.0 & 0.2 & 0.2 & 14.5 & 0.1 \\
\hline Gluteus Maximus (Superior) & & 0.0 & 0.0 & 49.3 & 248.9 & 1.9 & 0.0 \\
\hline Gluteus Maximus (Medial) & & 0.0 & 0.0 & 96.4 & 460.8 & 0.0 & 0.1 \\
\hline Gluteus Maximus (Inferior) & & 0.0 & 0.0 & 0.4 & 43.8 & 0.0 & 47.5 \\
\hline Gluteus Medius (Anterior) & & 99.7 & 101.3 & 20.6 & 516.1 & 101.9 & 0.0 \\
\hline Gluteus Medius (Medial) & & 0.0 & 0.0 & 52.5 & 262.1 & 41.7 & 0.0 \\
\hline Gluteus Medius (Posterior) & & 0.0 & 0.0 & 99.8 & 329.2 & 95.2 & 0.0 \\
\hline Gluteus Minimus (Anterior) & & 3.4 & 3.4 & 2.4 & 47.7 & 23.8 & 0.0 \\
\hline Gluteus Minimus (Medial) & & 0.0 & 0.0 & 9.1 & 77.4 & 28.9 & 0.0 \\
\hline Gluteus Minimus (Posterior) & & 0.0 & 0.0 & 28.8 & 137.2 & 30.6 & 0.0 \\
\hline Gracilis & & 4.2 & 5.9 & 0.0 & 0.0 & 0.0 & 2.7 \\
\hline Iliacus & & 62.1 & 122.1 & 0.0 & 0.0 & 604.6 & 6.8 \\
\hline Pectineus & & 13.3 & 20.0 & 0.0 & 0.0 & 0.1 & 2.4 \\
\hline Piriformis & & 0.0 & 0.0 & 37.8 & 185.8 & 53.2 & 0.1 \\
\hline
\end{tabular}




\begin{tabular}{|c|c|c|c|c|c|c|c|}
\hline Psoas & & 22.7 & 73.7 & 0.0 & 0.0 & 723.0 & 7.5 \\
\hline Quadriceps Femoris & & 0.0 & 0.0 & 4.2 & 0.0 & 26.3 & 2.7 \\
\hline Rectus Femoris & & 0.0 & 0.0 & 26.7 & 0.0 & 1011.2 & 0.2 \\
\hline Sartorius & & 0.0 & 0.0 & 2.5 & 0.4 & 20.7 & 0.2 \\
\hline Semimembranosis & & 82.5 & 81.4 & 1.0 & 377.6 & 0.0 & 42.8 \\
\hline Semitendinosis & & 11.1 & 12.7 & 0.1 & 20.0 & 0.0 & 9.0 \\
\hline Tensor Fasciae Latae & & 0.0 & 0.0 & 8.2 & 20.8 & 40.0 & 0.1 \\
\hline Knee joint & $\begin{array}{l}\text { Resultant force } \\
(\mathrm{N})\end{array}$ & $406.7 *$ & 375.6 & 29.7 & 894.8 & 647.3 & 53.3 \\
\hline Knee joint & $\begin{array}{l}\text { Resultant moment } \\
(\mathrm{Nm})\end{array}$ & $0.0 *$ & 18.9 & 8.7 & 41.0 & 20.5 & 11.7 \\
\hline Inertia & $\begin{array}{l}\text { Angular acceleration } \\
\text { resultant }\left(\mathrm{rad} / \mathrm{s}^{2}\right)\end{array}$ & 0.0 & 0.0 & 6.1 & 12.3 & 49.1 & 14.9 \\
\hline Inertia & $\begin{array}{l}\text { Linear acceleration } \\
\text { resultant }\left(\mathrm{m} / \mathrm{s}^{2}\right)\end{array}$ & 0.0 & 0.0 & 5.0 & 5.6 & 7.6 & 4.1 \\
\hline
\end{tabular}

* Load application point for training condition was at the distal end of the abutment rather than the knee joint. 
Table 3: Hip joint reaction force predicted by rigid body and finite element models for training, standing and during the stance phase of walking. The force components are provided in the local hip coordinate system*.

\begin{tabular}{|c|c|c|c|c|c|c|c|c|c|c|c|c|}
\hline & \multicolumn{2}{|c|}{$\begin{array}{l}\text { Standing: } \\
\text { Training } \\
\text { prosthesis }\end{array}$} & \multicolumn{2}{|c|}{$\begin{array}{l}\text { Standing: Full } \\
\text { lower limb } \\
\text { prosthesis }\end{array}$} & \multicolumn{2}{|c|}{$\begin{array}{l}\text { Ipsilateral heel } \\
\text { strike }\end{array}$} & \multicolumn{2}{|c|}{$\begin{array}{l}\text { Contralateral toe- } \\
\text { off }\end{array}$} & \multicolumn{2}{|c|}{$\begin{array}{c}\text { Contralateral heel } \\
\text { strike }\end{array}$} & \multicolumn{2}{|c|}{ Ipsilateral toe-off } \\
\hline & $\begin{array}{l}\text { Rigid- } \\
\text { body }\end{array}$ & $\begin{array}{l}\text { Finite } \\
\text { element }\end{array}$ & $\begin{array}{l}\text { Rigid- } \\
\text { body }\end{array}$ & $\begin{array}{l}\text { Finite } \\
\text { element }\end{array}$ & $\begin{array}{l}\text { Rigid- } \\
\text { body }\end{array}$ & $\begin{array}{c}\text { Finite } \\
\text { element }\end{array}$ & $\begin{array}{l}\text { Rigid- } \\
\text { body }\end{array}$ & $\begin{array}{c}\text { Finite } \\
\text { element }\end{array}$ & $\begin{array}{l}\text { Rigid- } \\
\text { body }\end{array}$ & $\begin{array}{l}\text { Finite } \\
\text { element }\end{array}$ & $\begin{array}{l}\text { Rigid- } \\
\text { body }\end{array}$ & $\begin{array}{l}\text { Finite } \\
\text { element }\end{array}$ \\
\hline $\mathrm{Fx}(\mathrm{N})$ & -192.0 & -191.8 & -331.7 & -331.5 & -76.5 & -74.5 & -731.4 & -728.9 & -767.8 & -767.1 & 29.1 & 27.7 \\
\hline Fy $(N)$ & -843.0 & -843.4 & -992.7 & -992.7 & -338.1 & -340.4 & -3215.2 & -3213.2 & -2884.1 & -2882.0 & -97.9 & -98.3 \\
\hline $\mathrm{Fz}(\mathrm{N})$ & 187.8 & 188.1 & 270.5 & 269.0 & 156.8 & 156.4 & 903.6 & 904.3 & 397.6 & 393.3 & 109.4 & 110.2 \\
\hline
\end{tabular}

${ }^{*}$ The positive $\mathrm{x}$-direction, $\mathrm{y}$-direction and $\mathrm{z}$-direction is anterior, superior and lateral, respectively. 
Table 4: Maximum von Mises stress (MPa) for the osseointegrated prosthesis, and maximum and minimum principal strains for the femoral cortical and trabecular bone. Data are given for standing as well as the stance phase of gait, including heel strike, contralateral toe-off, contralateral heel strike, and toe-off.

\begin{tabular}{|c|c|c|c|c|c|c|c|c|}
\hline Section & Variable & Component & $\begin{array}{l}\text { Standing: } \\
\text { Training } \\
\text { prosthesis }\end{array}$ & $\begin{array}{l}\text { Standing: } \\
\text { Full } \\
\text { lower } \\
\text { limb } \\
\text { prosthesis }\end{array}$ & $\begin{array}{l}\text { Ipsilateral } \\
\text { heel } \\
\text { strike }\end{array}$ & $\begin{array}{l}\text { Contralateral } \\
\text { toe-off }\end{array}$ & $\begin{array}{l}\text { Contralateral } \\
\text { heel strike }\end{array}$ & $\begin{array}{l}\text { Ipsilateral } \\
\text { toe-off }\end{array}$ \\
\hline \multirow[t]{2}{*}{ Implant } & \multirow{6}{*}{$\begin{array}{l}\text { von Mises } \\
\text { stress } \\
(\mathrm{MPa})\end{array}$} & $\begin{array}{l}\text { Intramedullary } \\
\text { stem }\end{array}$ & 132.7 & 140.5 & 39.8 & 522.8 & 475.4 & 25.6 \\
\hline & & Cross-screw & 126.8 & 131.0 & 39.9 & 501.8 & 451.6 & 11.2 \\
\hline \multirow{4}{*}{$\begin{array}{l}\text { Cortical } \\
\text { bone }\end{array}$} & & Femoral neck & 12.0 & 13.7 & 5.4 & 52.5 & 74.8 & 1.6 \\
\hline & & Intertrochanteric & 18.8 & 41.1 & 17.0 & 98.0 & 51.4 & 3.3 \\
\hline & & Subtrochanteric & 6.1 & 10.3 & 4.8 & 38.2 & 82.6 & 4.8 \\
\hline & & Diaphysis & 23.2 & 34.7 & 3.5 & 78.4 & 26.0 & 13.9 \\
\hline \multirow[t]{2}{*}{$\begin{array}{l}\text { Trabecular } \\
\text { bone } \\
\text { surrounding } \\
\text { implant }\end{array}$} & $\begin{array}{l}\text { Max, Min } \\
\text { Principal } \\
\text { Strain (\%) }\end{array}$ & $\begin{array}{l}\text { All regions of } \\
\text { femur }\end{array}$ & $0.22,-0.20$ & $0.26,-0.21$ & $\begin{array}{c}0.12,- \\
0.12\end{array}$ & $0.84,-0.80$ & $1.15,-0.74$ & $0.20,-0.12$ \\
\hline & & Femoral neck & $0.12,-0.20$ & $0.14,-0.21$ & $\begin{array}{c}0.06,- \\
0.08\end{array}$ & $0.52,-0.73$ & $0.41,-0.61$ & $0.03,-0.05$ \\
\hline \multirow{3}{*}{$\begin{array}{l}\text { Trabecular } \\
\text { bone }\end{array}$} & $\begin{array}{l}\text { Max, Min } \\
\text { Principal }\end{array}$ & Intertrochanteric & $0.25,-0.17$ & $0.54,-0.38$ & $\begin{array}{c}0.11,- \\
0.13\end{array}$ & $0.75,-0.79$ & $0.46,-0.62$ & $0.03,-0.03$ \\
\hline & Strain (\%) & Subtrochanteric & $0.04,-0.06$ & $0.05,-0.08$ & $\begin{array}{c}0.03,- \\
0.03\end{array}$ & $0.21,-0.27$ & $0.40,-0.32$ & $0.07,0.02$ \\
\hline & & Diaphysis & $0.24,-0.14$ & $0.28,-0.20$ & $\begin{array}{c}0.13,- \\
0.09\end{array}$ & $0.84,-0.80$ & $1.15,-0.74$ & $0.20,-0.14$ \\
\hline
\end{tabular}




\section{FIGURE CAPTIONS}

Figure 1: Osseointegrated transfemoral implant modelled in the present study prior to failure by early loosening. The specific regions of the intramedullary stem and cross-screw are indicated, as well as their implanted position in the femur.

Figure 2: $\quad$ Comparison of relative positions of initial osseointegrated implant and femur obtained using CT to the positions of the revised osseointegrated implant and femur obtained using frontal plane X-ray including frontal plane X-ray following the revision surgery, with the 3D geometry of the initial implant and femur aligned to the outline of the femur (a) frontal plane x-ray with segmented outlines indicating the femur (purple), revised implant (green) and the cavity from the removed cross-screw (blue), (b) 3D geometry of initial implant and femur (c), and 2D geometry of femur, revised implant (intramedullary stem) and the cavity from the removed cross-screw (d).

Figure 3: Framework for developing personalised computational model of the residual limb of a transfemoral amputee including over-ground walking experiments performed in a human movement laboratory (a), rigid-body musculoskeletal model of amputee (b), and details of the transfemoral osseointegrated implant, including the intramedullary stem and crossscrew (c), and finite element model of osseointegrated implant and femur (d). Muscle forces are indicated by red arrows. The multi-point constraint (MPC) connection indicated by the blue lines was used to transmit the 
knee reaction force $\left(\mathrm{F}_{\mathrm{knee}}\right)$ and moment $\left(\mathrm{M}_{\mathrm{knee}}\right)$ to the prosthesis abutment. The muscles rectus femoris, sartorius and tensor fasciae latae are omitted for visualization purposes.

Figure 4: $\quad$ Tasks modelled in the present study including standing using a training prosthesis (a), and full lower limb prosthesis (b). Also investigated was the stance phase of gait with the complete lower limb prosthesis including ipsilateral heel strike (c) contralateral toe-off (d) contralateral heel strike (e), and ipsilateral toe-off (f).

Figure 5: $\quad$ Regions of the femur used in the finite element model analysis. These included the femoral neck, intertrochanteric, subtrochanteric and diaphysis.

Figure 6: Von-Mises stress distribution in the osseointegrated implant for each load case. The location of the peak stress for the stem and screw are reported for standing using a training prosthesis (a), and full lower limb prosthesis (b). Stress distributions were also investigated for the stance phase of gait with the complete lower limb prosthesis including ipsilateral heel strike (c) contralateral toe-off (d) contralateral heel strike (e), and ipsilateral toe-off (f).

Figure 7: $\quad$ Von-Mises stress distribution in the femoral cortical bone for each load case. The location of the peak stress for the entire femur is indicated for standing using a training prosthesis (a), and full lower limb prosthesis (b). Stress distributions were also investigated for the stance phase of gait with the complete lower limb prosthesis including ipsilateral heel strike (c) 
contralateral toe-off (d) contralateral heel strike (e), and ipsilateral toe-off (f).

Figure 8: The maximum and minimum principal strain (top row and bottom row, respectively) in the trabecular bone surrounding the implant. Regions of bone exceeding the trabecular yield strength are shown in grey. Data are given for standing using a training prosthesis (a), and full lower limb prosthesis (b). Data are also provided for the stance phase of gait with the complete lower limb prosthesis including ipsilateral heel strike (c) contralateral toe-off (d) contralateral heel strike (e), and ipsilateral toe-off (f). 
Figure 1

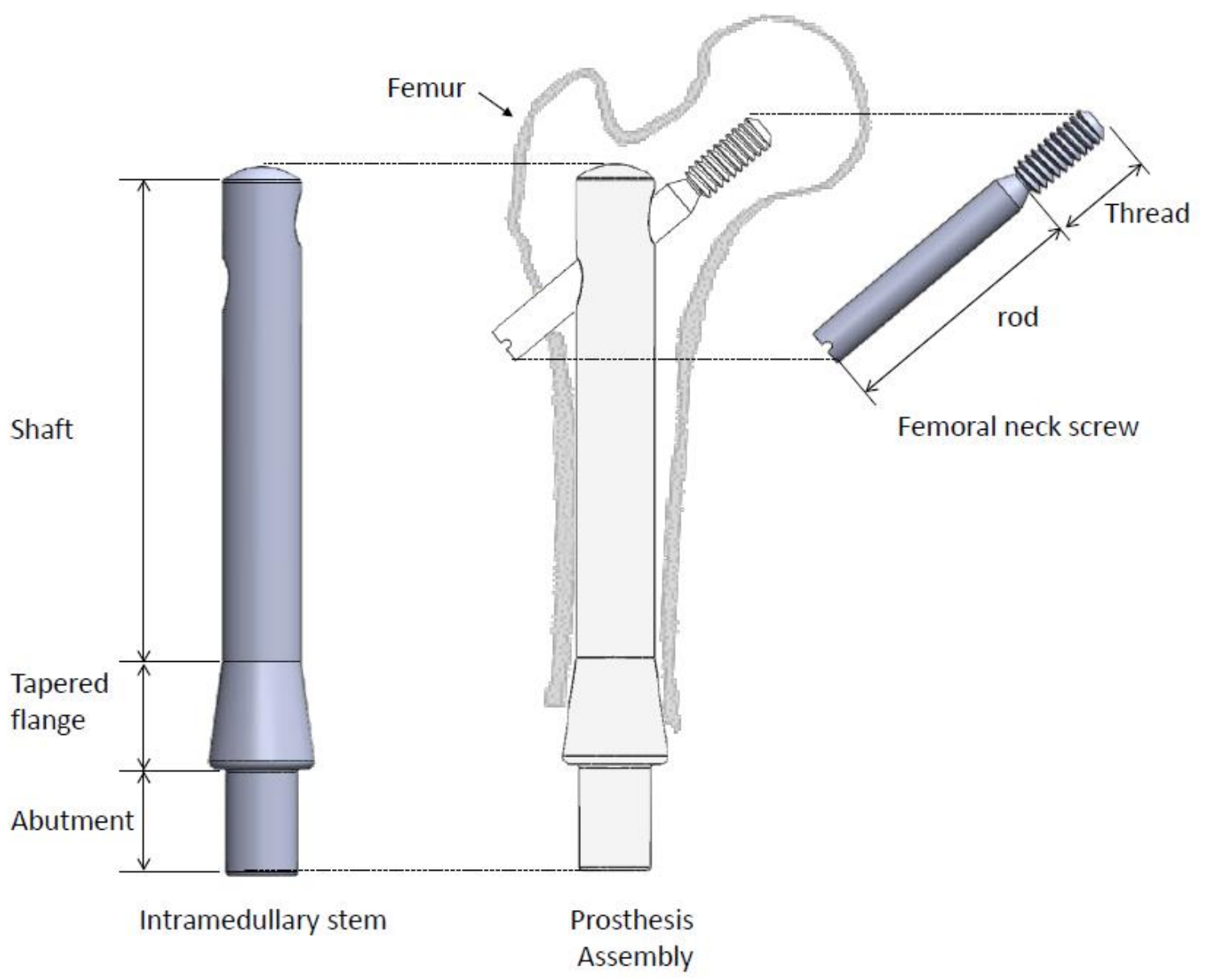


Figure 2

(a)

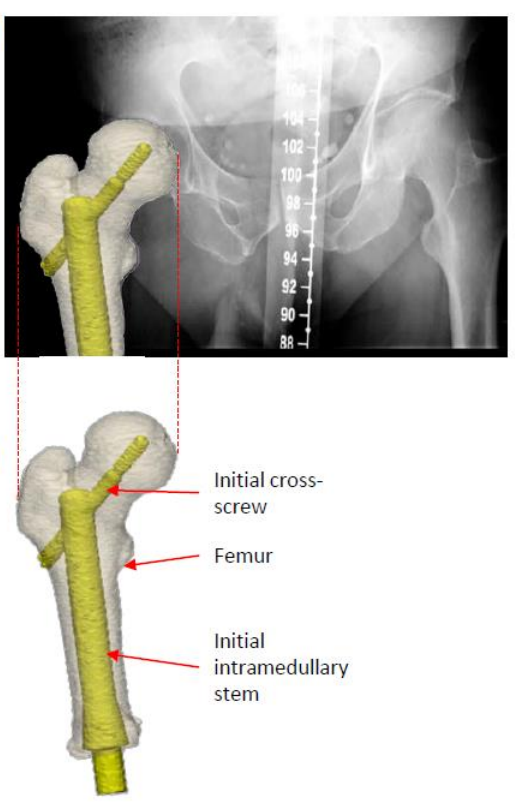

(b)

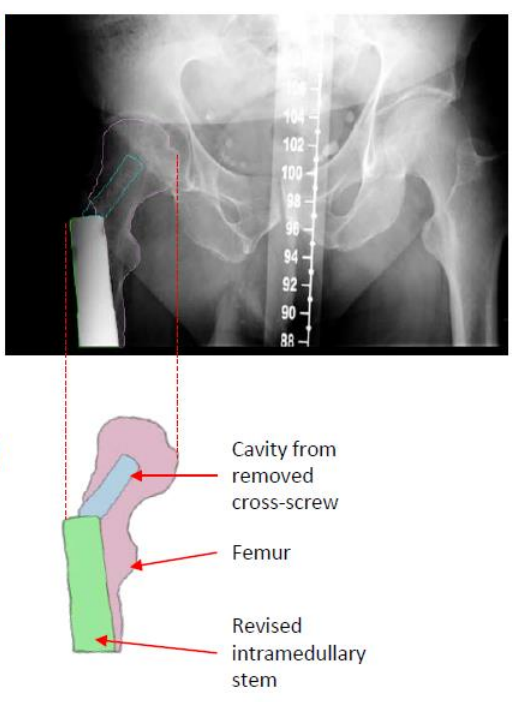

(e)

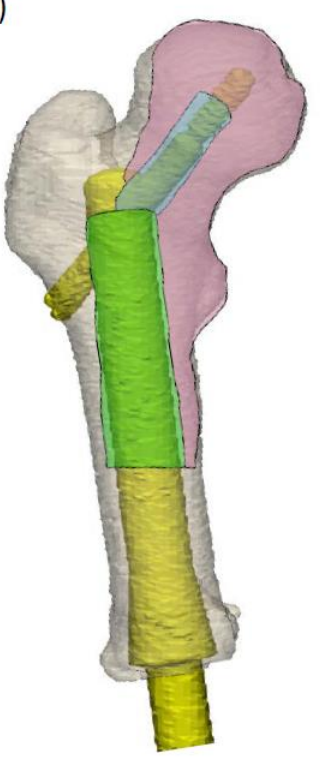


Figure 3

(a)

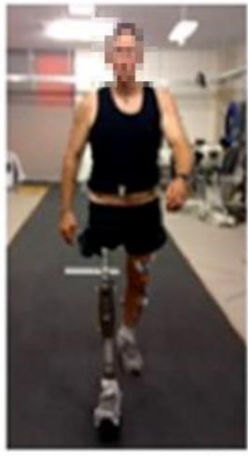

(b)

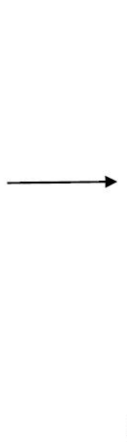

(c)

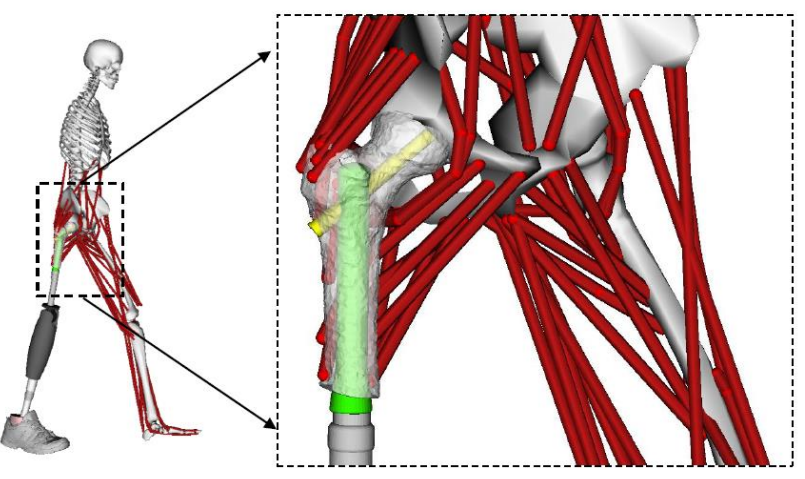

(d)

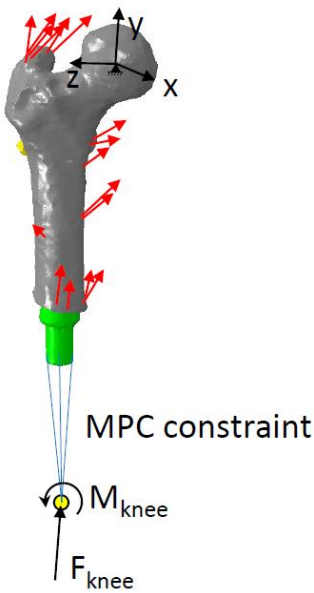


Figure 4

(a)

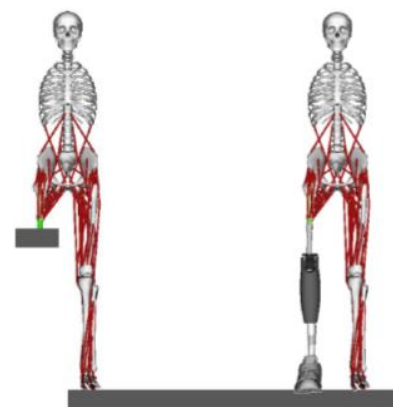

(c)

(d)

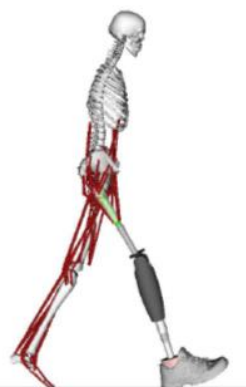

(e)

(f)

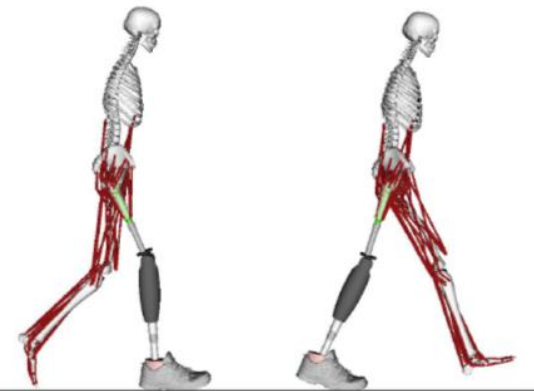

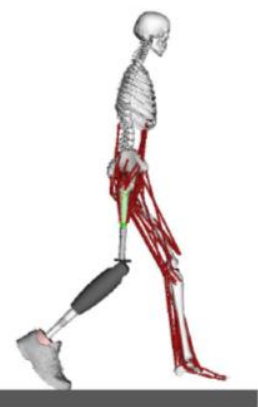


Figure 5

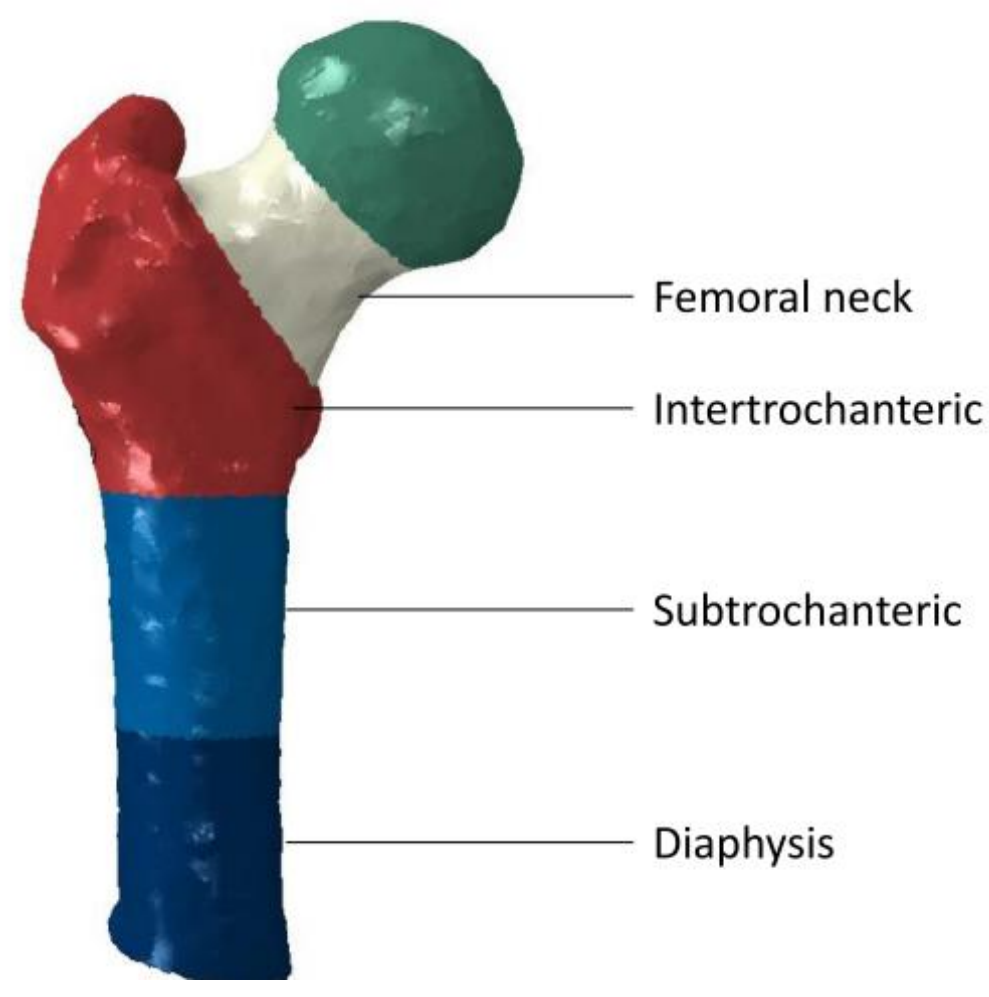


Figure 6

(a)

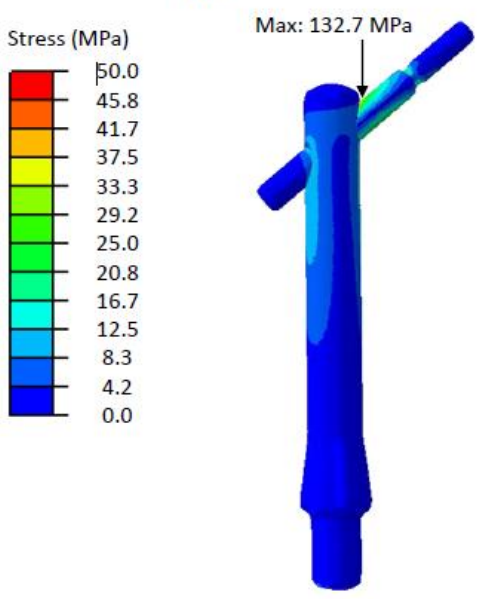

(d)

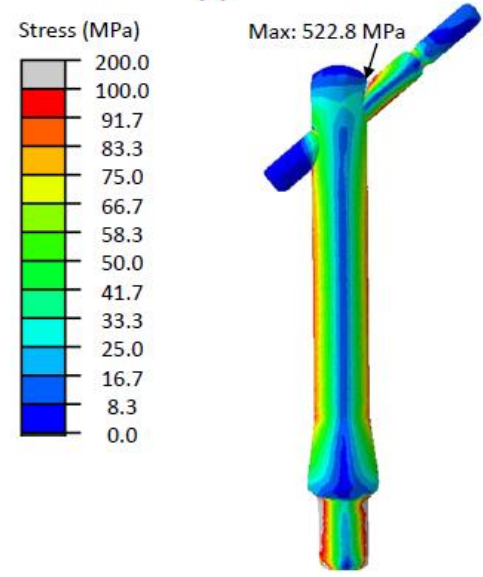

(b)

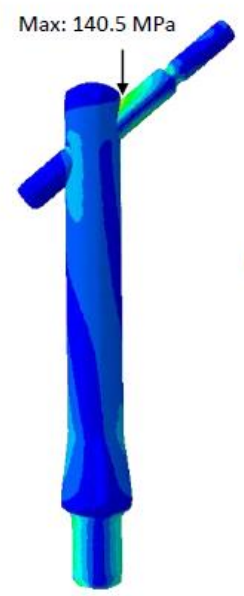

(e)

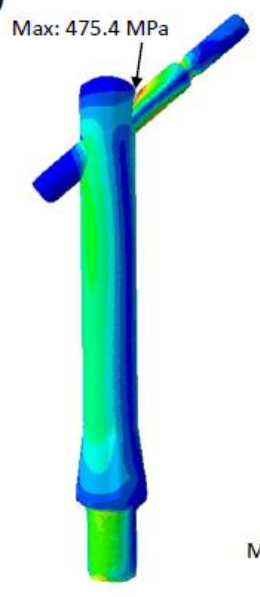

(c)

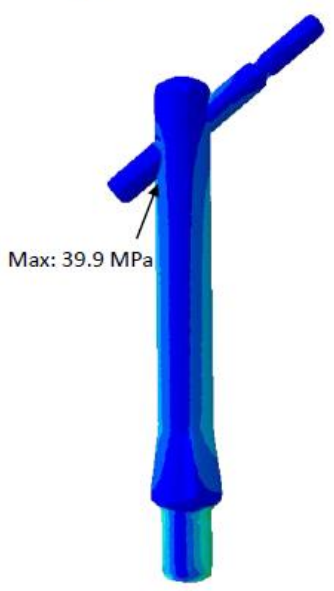

(f)

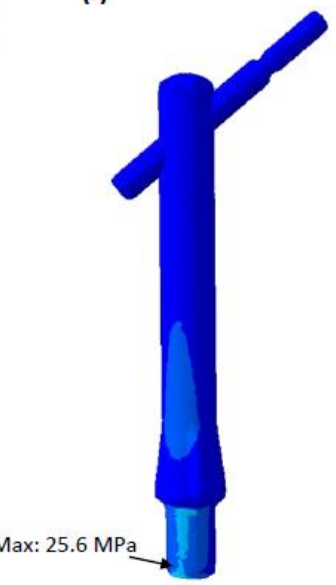


Figure 7

(a)

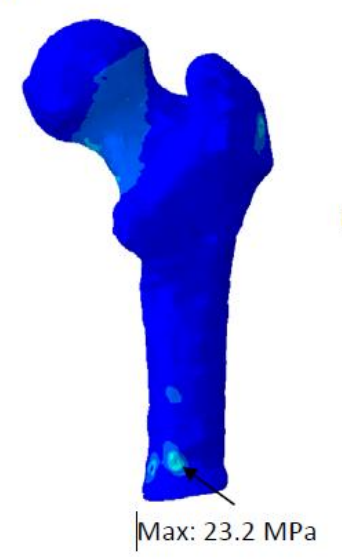

(d)

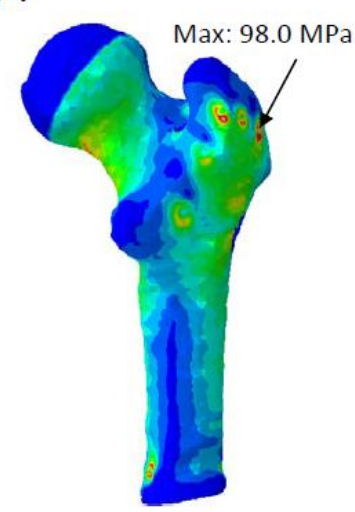

(b)

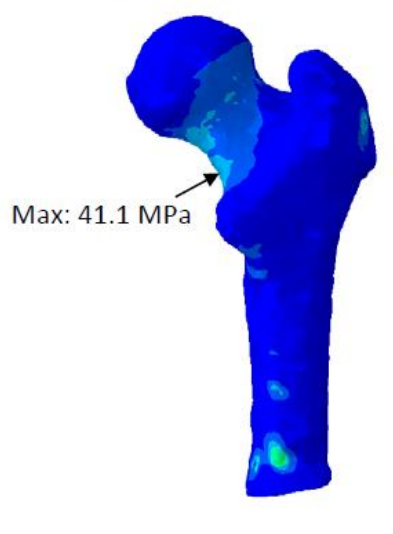

(e)

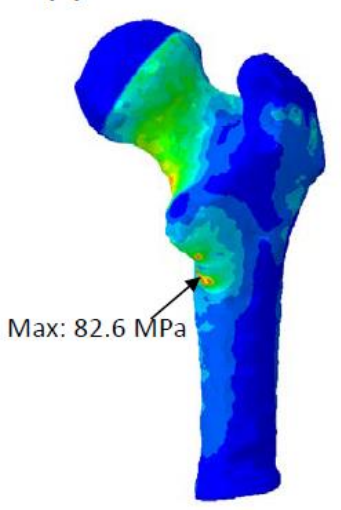

(c)

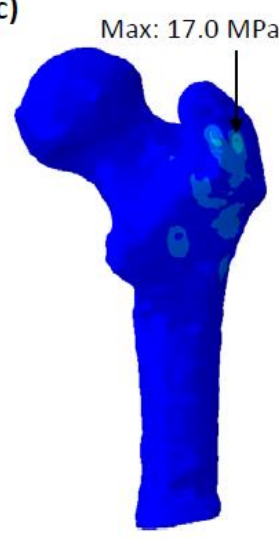

(f)

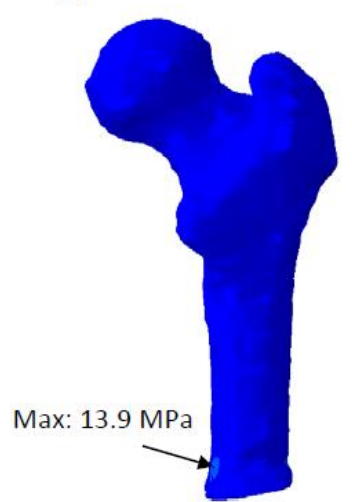


Figure 8

(a)

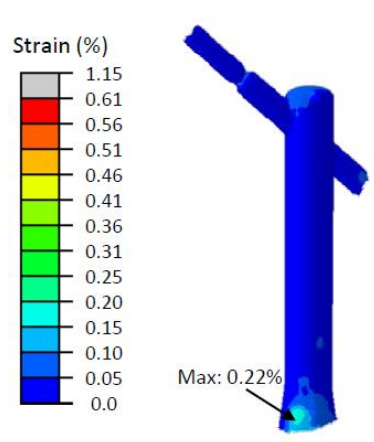

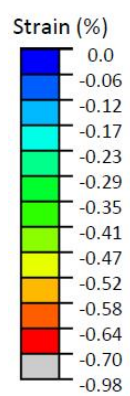

(b)
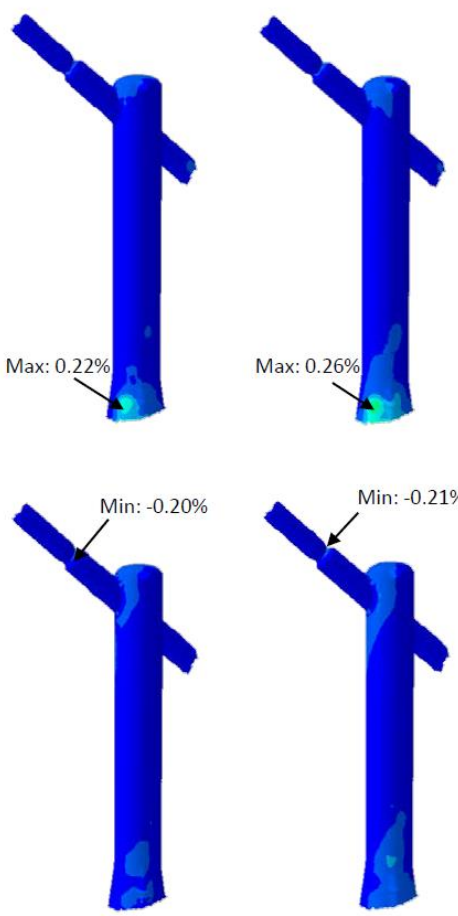

(c)
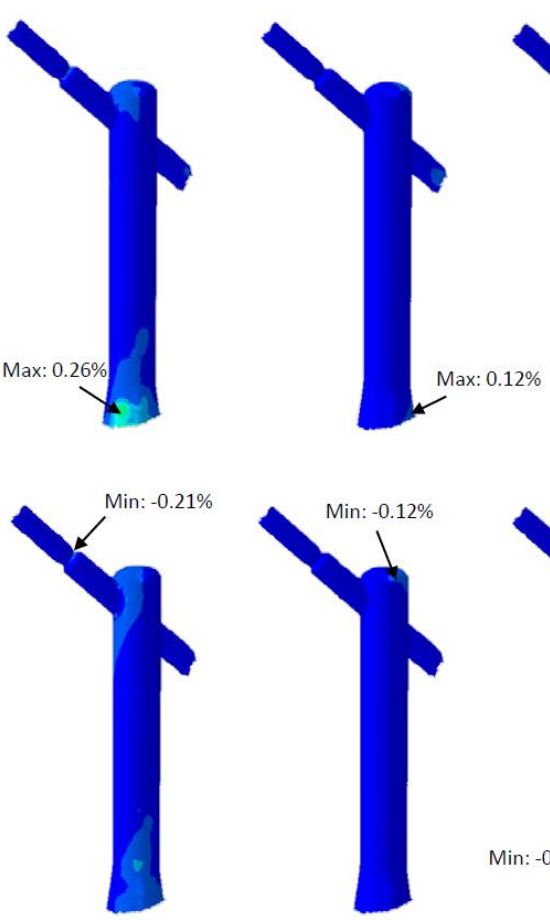

(d)

(e)

(e)
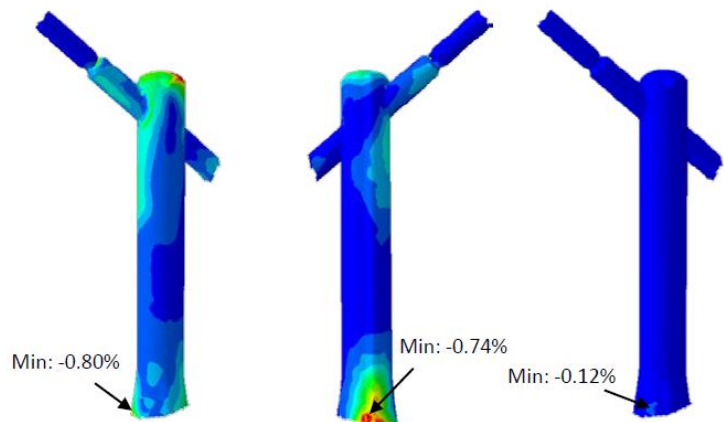


\section{University Library}

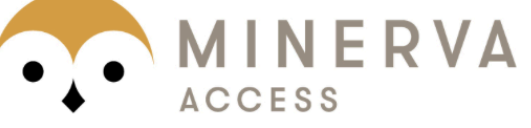

A gateway to Melbourne's research publications

Minerva Access is the Institutional Repository of The University of Melbourne

\section{Author/s:}

Robinson, DL;Safai, L;Harandi, VJ;Graf, M;Lizama, LEC;Lee, P;Galea, MP;Khan, F;Tse, KM;Ackland, DC

Title:

Load response of an osseointegrated implant used in the treatment of unilateral transfemoral amputation: An early implant loosening case study.

Date:

2020-03

\section{Citation:}

Robinson, D. L., Safai, L., Harandi, V. J., Graf, M., Lizama, L. E. C., Lee, P., Galea, M. P., Khan, F., Tse, K. M. \& Ackland, D. C. (2020). Load response of an osseointegrated implant used in the treatment of unilateral transfemoral amputation: An early implant loosening case study.. Clin Biomech (Bristol, Avon), 73, pp.201-212. https://doi.org/10.1016/ j.clinbiomech.2020.01.017.

Persistent Link:

http://hdl.handle.net/11343/249517 